\section{The Work Productivity and Activity Impairment Allergic Specific (WPAI-AS) Questionnaire Using Mobile Technology: The MASK Study}

Bousquet $\mathrm{J}^{1,2}$, VandenPlas $\mathrm{O}^{3}$, Bewick $\mathrm{M}^{4}$, Arnavielhe $\mathrm{S}^{5}$, Bedbrook $\mathrm{A}^{1}$, Murray $\mathrm{R}^{6}$, van Eerd $\mathrm{M}^{7}$, Fonseca $\mathrm{J}^{8}$, MoraisAlmeida $\mathrm{M}^{9}$, Todo Bom $\mathrm{A}^{10}$, Cruz $\mathrm{AA}^{11}$, Sarquis Serpa $\mathrm{F}^{12}$, da Silva $\mathrm{J}^{13}$, Menditto $\mathrm{E}^{14}$, Passalacqua $\mathrm{G}^{15}$, Stellato $\mathrm{C}^{16}$, Ventura $\mathrm{MT}^{17}$, Caimmi ${ }^{18}$, Demoly $\mathrm{P}^{18}$, Bergmann $\mathrm{KC}^{19}$, Keil $\mathrm{T}^{20}$, Klimek L ${ }^{21}$, Mösges $\mathrm{R}^{22}$, Shamai $\mathrm{S}^{22}$, Zuberbier $\mathrm{T}^{19}$, Larenas-Linnemann $\mathrm{D}^{23}$, Rodriguez Gonzalez $\mathrm{M}^{24}$, Burguete Cabañas $\mathrm{MT}^{25}$, Ryan $\mathrm{D}^{26}$, Sheikh A ${ }^{27}$, Anto $\mathrm{JM}^{28}$, Mullol J ${ }^{29}$, Valero $\mathrm{A}^{29}$, Kowalski $\mathrm{ML}^{30}$, Kuna $\mathrm{P}^{31}$, Samolinski B ${ }^{32}$, Tomazic $\mathrm{PV}^{33}$, Bosnic-Anticevich $\mathrm{S}^{34}$, $\mathrm{O}^{\prime}$ Hehir RE ${ }^{35}$, De Vries $\mathrm{G}^{7}$, Laune $\mathrm{D}^{5}$

${ }^{1}$ MACVIA-France, Contre les MAladies Chroniques pour un VIeillissement Actif en France European Innovation Partnership on Active and Healthy Ageing Reference Site, Montpellier, France ${ }^{2}$ INSERM U 1168, VIMA: Ageing and chronic diseases Epidemiological and public health approaches, Villejuif, Université Versailles St-Quentin-en-Yvelines, UMR-S 1168, Montigny le Bretonneux, France and Euforea, Brussels, Belgium ${ }^{3}$ Department of Chest Medicine, Centre Hospitalier Universitaire UCL Namur, Université Catholique de Louvain, Yvoir, Belgium ${ }^{4} i Q 4 U$ Consultants Ltd, London, UK

${ }^{5}$ Kyomed, Montpellier, France

${ }^{6}$ Medical Communications Consultant, MedScript Ltd, Dundalk, Co Louth, Ireland

${ }^{7}$ Peercode DV, Gerdermalsen, The Netherlands

${ }^{8}$ Center for Health Technology and Services Research-CINTESIS, Faculdade de Medicina, Universidade do Porto; and Allergy Unit, CUF Porto Instituto \& Hospital, Porto, Portugal

${ }^{9}$ Allergy Center, CUF-Descobertas Hospital, Lisboa, Portugal

${ }^{10}$ Imunoalergologia, Centro Hospitalar Universitário de Coimbra and Faculty of Medicine, University of Coimbra, Portugal ${ }^{11}$ ProAR - Nucleo de Excelencia em Asma, Federal University of Bahia, Brazil and GARD Executive Committee, Brazil

${ }^{12}$ Asthma Reference Center, Escola Superior de Ciencias da Santa Casa de Misericordia de Vitoria, ES, Brazil

${ }^{13}$ Allergy Service, University Hospital of Federal University of Santa Catarina (HU-UFSC), Florianopolis, SC, Brazil

${ }^{14} \mathrm{CIRFF}$, Center of Pharmacoeconomics, University of Naples Federico II , Naples, Italy

${ }^{15}$ Allergy and Respiratory Diseases, Policlinico San Martino, University of Genoa, Genoa, Italy

${ }^{16}$ Department of Medicine, Surgery and Dentistry "Scuola Medica Salernitana", University of Salerno, Salerno, Italy

${ }^{17}$ University of Bari Medical School, Unit of Geriatric Immunoallergology, Bari, Italy

${ }^{18}$ CHRU de Montpellier, Sorbonne Universités, UPMC Paris 06, UMR-S 1136, IPLESP, Equipe EPAR, F-75013 Paris, France
${ }^{19}$ Comprehensive Allergy-Centre-Charité, Department of Dermatology and Allergy, Charité - Universitätsmedizin Berlin; Global Allergy and Asthma European Network (GA2LEN), Berlin, Germany

${ }^{20}$ Institute of Social Medicine, Epidemiology and Health Economics, Charité - Universitätsmedizin Berlin, Berlin, and Institute for Clinical Epidemiology and Biometry, University of Wuerzburg, Germany

${ }^{21}$ Center for Rhinology and Allergology, Wiesbaden, Germany

${ }^{22}$ Institute of Medical Statistics, and Computational Biology, Medical Faculty, University of Cologne, Germany and CRIClinical Research International-Ltd Hamburg, Germany

${ }^{23}$ Center of Excellence in Asthma and Allergy, Hospital Médica Sur, México City, Mexico

${ }^{24}$ Pediatric Allergy and Clinical Immunology, Hospital Angeles Pedregal, Mexico City, Mexico

${ }^{25}$ Centro Médico Zambrano Hellion, Monterrey, Mexico

${ }^{26}$ Allergy and Respiratory Research Group, Usher Institute of Population Health Sciences and Informatics, University of Edinburgh, UK

${ }^{27}$ Director, Asthma UK Centre for Applied Research, Centre of Medical Informatics, Usher Institute of Population Health Sciences and Informatics, The University of Edinburgh, Edinburgh, UK

${ }^{28}$ ISGoBAL, Centre for Research in Environmental Epidemiology (CREAL), Barcelona, Spain; IMIM (Hospital del Mar Research Institute), Barcelona, Spain; CIBER Epidemiología y Salud Pública (CIBERESP), Barcelona, Spain; Universitat Pompeu Fabra (UPF), Barcelona, Spain

${ }^{29}$ Rhinology Unit \& Smell Clinic, ENT Department, Hospital Clínic; Clinical \& Experimental Respiratory Immunoallergy, IDIBAPS, CIBERES, University of Barcelona, Barcelona, Spain. ${ }^{30}$ Department of Immunology, Rheumatology and Allergy, Medical University of Lodz, and HARC, Poland.

${ }^{31}$ Division of Internal Medicine, Asthma and Allergy, Barlicki University Hospital, Medical University of Lodz, Poland.

${ }^{32}$ Department of Prevention of Envinronmental Hazards and Allergology, Medical University of Warsaw, Poland.

${ }^{33}$ Department of ENT, Medical University of Graz, Austria

${ }^{34}$ Woolcock Institute of Medical Research, University of Sydney and Sydney Local Health District, Glebe, NSW, Australia.

${ }^{35}$ Department of Allergy, Immunology and Respiratory Medicine, Alfred Hospital and Central Clinical School, Monash University, Melbourne, Victoria, Australia; Department of Immunology, Monash University, Melbourne, Victoria, Australia.

J Investig Allergol Clin Immunol 2018; Vol. 28(1): $42-44$ doi: 10.18176/jiaci.0197

Key words: Rhinitis. ARIA. MASK. WPAI-AS. Work productivity. Activity.

Palabras clave: Rinitis. ARIA. MASK. WPAI-AS. Productividad en el trabajo. Actividad. 
Uncontrolled allergic and nonallergic rhinitis have a major impact on work productivity and absenteeism [1]. The Work Productivity and Activity Impairment Allergic Specific Questionnaire (WPAI-AS) has been used in many studies [2-7]. Impaired work productivity assessed using the WPAI-AS has been associated with the severity of allergic rhinitis (AR) [7]. Using mobile technology-based visual analog scales, we previously found that work productivity was impaired in moderate/severe AR [8].

MASK-rhinitis (MACVIA-ARIA Sentinel NetworK for allergic rhinitis) is a patient-centered information and communications technology system [9] based on a mobile phone app (Allergy Diary). Users are asked to complete a short demographic questionnaire and the WPAI-AS to provide baseline characteristics of their disease. The Allergy Diary has been launched in 21 countries.

In order to better assess the loss of work productivity in AR, we tested the WPAI-AS using the Allergy Diary.

A cross-sectional study was carried out in all consecutive users of the Allergy Diary (12 636) who completed the WPAIAS from June 1, 2016 to July 31, 2017. The Allergy Diary has been described elsewhere [8,10]. The app collects information on AR symptoms experienced (nasal and ocular), disease type (intermittent/persistent), how symptoms impact users' lives, and type(s) of AR treatment used. The system has been deployed in 21 countries and in 16 languages (translated and back-translated, culturally adapted, and legally compliant). The data are anonymized, except for geographic data, which are never totally anonymous. Independent Review Board approval was not needed.

The electronic form of the WPAI-AS Questionnaire was applied in the 7 available languages (ie, English, French, German, Italian, Polish, Portuguese, and Spanish) [8,10] according to the package obtained from Reilly Associates (www.reillyassociates.net/WPAI General.html). The outcomes used were the percentages of impairment due to allergy for daily activities (Q9: degree allergy affected regular activities) or work productivity (Q4: degree allergy affected productivity while working).

Since the results were not normally distributed for Q4 and Q9 (Shapiro-Wilk test), values were expressed as median (IQR), and nonparametric tests were used.

Of the 12636 registered users, 1017 completed Q9 and 698 Q4 (Table online). There were 629 women (61\%) and 405 men $(39 \%)$, with a mean age of $26(16)$ years. The number of users per country was distributed as follows:

$\begin{array}{ll}\text { - Austria } & 7 \\ \text { - Australia } & 6 \\ \text { - Brazil } & 198 \\ \text { - Canada } & 3 \\ \text { - France } & 126 \\ \text { - Germany } & 96 \\ \text { - Italy } & 126 \\ \text { - Mexico } & 85 \\ \text { - Poland } & 43 \\ \text { - Portugal } & 294 \\ \text { - Spain } & 66 \\ \text { - Switzerland } & 89 \\ \text { - UK } & 73\end{array}$

Similar WPAI-AS percentages of impairment were found for Q4 ( $\mathrm{N}=698$; median, 20 [4-50]) and for Q9 $(\mathrm{N}=1017$; median, 17 [3-45]).

There was a highly significant correlation between the 2 questions. For a Q4 percentage of impairment of over $50 \%$, all but 1 user reported no impairment in work productivity. In users with Q4 $\geq 50,18 \%$ had a $Q 9<50$.

Analysis of data from this pilot ICT-based care system for AR revealed that the level of work impairment is highly correlated with the degree that allergy affected regular activities using the 2 validated questions of the WPAI-AS on global and work impairment.

The strengths and limitations of this study are those of mobile technology, which have been discussed at length elsewhere $[8,10]$. A key limitation was the lack of patient characterization, which is impossible using an app. However, every observational study we have performed using the Allergy Diary has confirmed the potential to identify users with severe disease. It is likely that mobile technology will become a very important tool in our understanding and management of AR.

The WPAI-AS scores observed in the study are lower than those reported in patients selected by physicians [2-7]. This is because many users have mild rhinitis, whereas in clinical trials or in patients selected by physicians, AR is usually more severe.

The results of the study are in line with those of 2 previous studies using the same app. All 3 studies used different but complementary tools. In the first study, a global question was asked at baseline ("How do my symptoms affect my school or work?") [10], and it was found that impairment was associated with troublesome symptoms, ocular symptoms, and nasal obstruction. In the second study, the result of the visual analog scale was correlated with global allergy symptoms $(\mathrm{N}=5678$ days; $\mathrm{rho}=0.82)$, rhinitis $(\mathrm{rho}=0.80)$, ocular symptoms $(\mathrm{rho}=0.70)$, and asthma $(\mathrm{rho}=0.56)$. In this third study, there was a highly significant correlation between the WPAI-AS questions Q4 (degree allergy affected productivity while working) and Q9 (degree allergy affected regular activities). Together, the findings from these studies indicate that 3 different tools used in a large number of countries and languages with cultural differences give very similar results. There is a very strong correlation between the severity of rhinitis and work productivity. However, as found in the 3 studies, some work impairment is also found in users with milder rhinitis symptoms.

Work productivity is a major problem in rhinitis patients. Those with severe symptoms almost always have some work impairment, although work impairment is not restricted to moderate and severe disease.

\section{Funding}

Funding was received in the form of an unrestricted educational grant from Meda, European Union Development and Structural funds (Région Languedoc Roussillon).

\section{Conflicts of Interest}

J Bousquet reports personal fees from Almirall, AstraZeneca, GSK, Meda, Merck, MSD, Takeda, Chiesi, 
Menarini, Mylan, Novartis, Uriach, Sanofi-Aventis, Teva, and Kyomed.

S Bosnic-Anticevich reports grants from TEVA pharmaceuticals and personal fees from TEVA pharmaceuticals, GSK, AstraZeneca, and Boehringer Ingelheim.

L Klimek reports grants and personal fees from ALK Abelló (Denmark), Novartis (Switzerland), Allergopharma (Germany) and personal fees from MEDA (Sweden), Bionorica (Germany), GSK (Great Britain), Lofarma (Italy), Boehringer Ingelheim (Germany) and grants from Biomay (Austria) HAL (Netherlands) LETI (Spain), Roxall, (Germany) Bencard (Great Britain).

P Kuna reports personal fees from Berlin Chemie Menarini, personal fees from FAES, personal fees from ALK, personal fees from Hal, personal fees from Allergopharma, personal fees from Adamed, and personal fees from Polpharma outside the present study.

D Larenas-Linnemann reports being Chair of the immunotherapy committee of the CMICA, a member of immunotherapy committees or interest groups (EAACI, WAO, SLAAI), and being on the Board of Directors and Program Chair of CMICA 2018-2019.

$\mathrm{R}$ Mösges reports personal fees from Allergopharma, ALK, Allergy Therapeutics, Johnson \& Johnson, Nuvo, Stada, UCB, FAES, GSK, MSD, Friulchem, and Hexal and grants from ASIT biotech, BitopAG, Hulka, Leti, Optima, and Ursapharm; R Mösges also reports grants and personal fees from Bencard, and Stallergenes and grants, personal fees, and nonfinancial support from Lofarma, nonfinancial support from Atmos, Bionorica, Ferrero Otonomy, and Roxall and personal fees and nonfinancial support from Novartis.

A Todo-Bom reports grants and personal fees from Novartis, Bayer, Boehringer Ingelheim, Mundipharma, GSK (GlaxoSmithKline) and personal fees from Teva Pharma and AstraZeneca, Meda, Servier, and Klosterfrau.

$\mathrm{T}$ Zuberbier is a committee member with the WHOInitiative "Allergic Rhinitis and Its Impact on Asthma" (ARIA), a Member of the Board of the German Society for Allergy and Clinical Immunology (DGAKI), Head of the European Centre for Allergy Research Foundation (ECARF), Secretary General of the Global Allergy and Asthma European Network ( $\left.\mathrm{Ga}^{2} \mathrm{len}\right)$, and a member of the Committee on Allergy Diagnosis and Molecular Allergology of the World Allergy Organization (WAO).

The remaining authors declare that they have no conflicts of interest.

\section{References}

1. Ojeda P, Sanz de Burgoa V, Coste Asma S. Costs associated with workdays lost and utilization of health care resources because of asthma in daily clinical practice in Spain. J Investig Allergol Clin Immunol. 2013;23(4):234-41.

2. Bousquet J, Neukirch F, Bousquet PJ, Gehano P, Klossek JM, Le Gal M, et al. Severity and impairment of allergic rhinitis in patients consulting in primary care. J Allergy Clin Immunol. 2006;117(1):158-62.
3. Stull DE, Roberts L, Frank L, Heithoff K. Relationship of nasal congestion with sleep, mood, and productivity. Curr Med Res Opin. 2007;23(4):811-9.

4. Bousquet J, Bodez T, Gehano P, Klossek JM, Liard F, Neukirch $F$, et al. Implementation of Guidelines for Allergic Rhinitis in Specialist Practices. A Randomized Pragmatic Controlled Trial. Int Arch Allergy Immunol. 2009;150(1):75-82.

5. Mansfield LE, Hampel F, Haeusler JM, Georges G. Study of levocetirizine in seasonal allergic rhinitis. Curr Med Res Opin. 2010;26(6):1269-75.

6. Meltzer EO, Munafo DA, Chung W, Gopalan G, Varghese ST. Intranasal mometasone furoate therapy for allergic rhinitis symptoms and rhinitis-disturbed sleep. Ann Allergy Asthma Immunol. 2010;105(1):65-74.

7. Colas C, Brosa M, Anton E, Montoro J, Navarro A, Dordal $M T$, et al. Estimate of the total costs of allergic rhinitis in specialized care based on real-world data: the FERIN Study. Allergy. 2017;72(6):959-66.

8. Bousquet J, Bewick M, Arnavielhe S, Mathieu-Dupas E, Murray $R$, Bedbrook $A$, et al. Work productivity in rhinitis using cell phones: The MASK pilot study. Allergy. 2017;72(10):1475-84.

9. Bousquet J, Hellings PW, Agache I, Bedbrook A, Bachert C, Bergmann KC, et al. ARIA 2016: Care pathways implementing emerging technologies for predictive medicine in rhinitis and asthma across the life cycle. Clin Transl Allergy. 2016;6:47.

10. Bousquet J, Caimmi DP, Bedbrook A, Bewick M, Hellings PW,

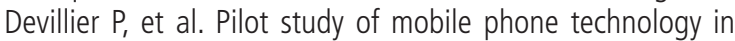
allergic rhinitis in European countries: the MASK-rhinitis study. Allergy. 2017;72(6):857-65.

Manuscript received August 23, 2017; accepted for publication August 28, 2017
Jean Bousquet

CHU Montpellier

71 Avenue du Doyen Gaston Giraud 34295 Montpellier Cedex 5, France E-mail: jean.bousquet@orange.fr 